\title{
Obesity and the Receipt of Prescription Pain Medications in the US
}

\author{
Gawon Cho, BA, $B B A^{7}$ and Virginia W. Chang, $M D, P h D^{1,2}$ (]) \\ 'Department of Social and Behavioral Sciences, School of Global Public Health, New York University, New York, NY, USA; ${ }^{2}$ Department of Population \\ Health, Grossman School of Medicine, New York University, New York, NY, USA.
}

BACKGROUND: Little is known about disparities in pain treatment associated with weight status despite prior research on weight-based discrepancies in other realms of healthcare and stigma among clinicians.

OBJECTIVE: To investigate the association between weight status and the receipt of prescription analgesics in a nationally representative sample of adults with back pain, adjusting for the burden of pain.

DESIGN: Cross-sectional analyses using the Medical Expenditure Panel Survey (2010-2017).

PARTICIPANTS: Five thousand seven hundred ninetyone civilian adults age $\geq 18$ with back pain.

MAIN MEASURES: We examine the odds of receiving prescription analgesics for back pain by weight status using logistic regression. We study the odds of receiving (1) any pain prescription, (2) three pain prescription categories (opioid only, non-opioid only, the combination of both), and (3) opioids conditional on having a pain prescription. KEY RESULTS: The odds of receiving pain prescriptions increase monotonically across weight categories, when going from normal weight to obesity II/III, despite adjustments for the burden of pain. Relative to normal weight, higher odds of receiving any pain prescription is associated with obesity I (OR = 1.30 [95\% CI = 1.04-1.63]) and obesity II/III (OR = 1.72 [95\% CI = 1.36-2.18]). Obesity II/III is also associated with higher odds of receiving opioids only $(\mathrm{OR}=$ 1.53 [95\% CI $=1.16-2.02]$ ), non-opioids only (OR $=1.77$ [95\% CI $=1.21-2.60]$ ), and a combination of both (OR = 2.48 [95\% CI = 1.44-4.29]). Obesity I is associated with increased receipt of non-opioids only $(\mathrm{OR}=1.55$ [95\% CI = 1.07-2.23]). Conditional on having a pain prescription, the odds of receiving opioids are comparable across weight categories.

CONCLUSIONS: This study suggests that, relative to those with normal weight, adults with obesity are more likely to receive prescription analgesics for back pain, despite adjustments of the burden of pain. Hence, the possibility of weight-based undertreatment is not supported. These findings are reassuring because individuals with obesity generally experience a higher prevalence of back pain. The possibility of over-treatment associated with obesity, however, may warrant further investigation.

KEY WORDS: obesity; pain; health disparities; pain medicine; opioids.

Supplementary Information The online version contains supplementary material available at https://doi.org/10.1007/s11606-020-06581-9.

Received July 28, 2020

Accepted December 29, 2020

Published online February 8, 2021
J Gen Intern Med 36(9):2631-8

DOI: $10.1007 /$ s11606-020-06581-9

(C) Society of General Internal Medicine 2021

\section{INTRODUCTION}

Racial and gender disparities in access to prescription ( $\mathrm{Rx})$ pain medicine have been studied extensively. ${ }^{1-11}$ Existing evidence indicates that racial minorities are less likely to receive $\mathrm{Rx}$ analgesics than whites despite having comparable need. ${ }^{1-6}$ Evidence on gender disparities is mixed, with some finding no difference in analgesic prescribing between males and females. ${ }^{6-11}$ Little is known, however, about disparities in pain treatment associated with obesity despite prior work documenting disparities in other realms of care and weightrelated bias among providers. ${ }^{12-18}$ For example, some research has shown that individuals with obesity are less likely to receive preventive care, such as influenza vaccination and screening for cervical and breast cancer. ${ }^{19-23}$ Obesity is also associated with reduced hospice care at the end of life, ${ }^{24}$ and patients with obesity are often denied arthroplasty that could alleviate pain. ${ }^{25,26}$ In terms of the patient encounter, obesity is associated with stereotypical beliefs held by healthcare providers (e.g., lack of motivation, poor self-control, low medication adherence), ${ }^{13,18}$ lower patient-clinician rapport, ${ }^{27}$ and shorter appointments. ${ }^{28}$ In a behavioral experiment where medical students were randomly assigned to provide care for a virtual patient who is either obese or non-obese with identical symptoms (e.g., shortness of breath), students assigned to treat the patient with obesity were more likely to provide lifestyle recommendations (e.g., weight loss), while their counterparts were more willing to prescribe a medication for symptom management. ${ }^{29}$ These findings suggest that obesityrelated stigma and bias may also affect the prescription of analgesics.

In this study, we examine the association between weight status and the receipt of prescription analgesics in a nationally representative sample of adults with back pain. We focus on back pain because it is a major cause of disability and reduced quality of life in the U.S., ${ }^{30,31}$ especially among individuals who are obese. ${ }^{32-37}$ Obesity is strongly associated with various back pain conditions (e.g., sciatica, lumbar disc degeneration), as well as the risk factors for back pain (e.g., increased loading of the spinal joints, reduced physical activity). ${ }^{32-38}$ 
Recent studies have shown a positive association between obesity and opioid use in the general population, presumably due to a higher prevalence of pain among those who are obese. $^{39,40}$ The studies focus on overall use irrespective of need or conditions, which does not speak to disparities in treatment. To focus on potential treatment disparities, we restrict our sample to persons with a given source of pain (back pain) and examine whether they received a pain prescription as treatment. In addition, we adjust for the burden of pain by accounting for the degree to which pain interferes with work activities. Here, we follow prior work using such variables to gage the appropriateness of analgesic treatment. ${ }^{1-10}$ We also extend the literature by examining the provision of both opioid and non-opioid analgesics. Prior work suggests that disparities in prescribing may be more pronounced for more potent medications. ${ }^{41,42}$

\section{METHODS}

\section{Data Source}

We use the Medical Expenditure Panel Survey (MEPS), a nationwide survey on health, healthcare use, and medical expenditure, administered by the Agency of Healthcare Research and Quality. ${ }^{43}{ }^{44}$ The MEPS is representative of the civilian noninstitutional population living in 50 US states and the District of Columbia. ${ }^{43}{ }^{44}$ A new panel of households is sampled each year and asked to complete five rounds of interviews spaced evenly over two years. ${ }^{43}$, ${ }^{44}$ In each round, information on all eligible members of a household is collected from one knowledgeable member (a household proxy) via computer-assisted, in-person interviews. $^{45-47}$ Information obtained during interviews is supplemented and verified by administrative data provided by medical providers, e.g., pharmacies and hospitals. $^{45,46}$ Also, each year, adult participants are asked to complete a mail-back Self-administered Adult Questionnaire (SAQ), which collects information on health and healthcare use, including pain interference. ${ }^{48}$ For more information on sampling frame and methodology, see to Chowdhury et al. ${ }^{44}$ Data from years 2010 to 2017 are pooled to increase sample size.

\section{Participants}

Our sample is civilian adults (age $\geq 18$ ) who reported experiencing back pain. During each wave, respondents are asked to report on health problems, which are coded by MEPS using International Classification of Diseases (ICD) codes. Following prior work on back pain using the MEPS and other population-based surveys, ${ }^{49-52}$ we use ICD codes to identify the sources of both upper and lower back pain (see Table 1 for codes). While data on health problems is collected in every round, data on pain interference is only available in rounds two and four. We examine those reporting back pain and their
Table 1 ICD codes for back pain

\begin{tabular}{|c|c|c|}
\hline Version & Diagnosis/definition & $\overline{\text { Code }}$ \\
\hline \multirow[t]{13}{*}{$\begin{array}{l}\text { Ninth revision } \\
(2010-2015)\end{array}$} & $\begin{array}{l}\text { Ankylosing spondylitis and other } \\
\text { inflammatory spondylopathies }\end{array}$ & 720 \\
\hline & Spondylosis and allied disorders & 721 \\
\hline & Intervertebral disc disorders & 722 \\
\hline & Other disorders of cervical region & 723 \\
\hline & Other and unspecified disorders of back & 724 \\
\hline & $\begin{array}{l}\text { Fracture of vertebral column without } \\
\text { mention of spinal cord injury }\end{array}$ & 805 \\
\hline & $\begin{array}{l}\text { Fracture of vertebral column with spinal } \\
\text { cord injury }\end{array}$ & 806 \\
\hline & $\begin{array}{l}\text { Other multiple and ill-defined disloca- } \\
\text { tions }\end{array}$ & 839 \\
\hline & Sprains and strains of sacroiliac region & 846 \\
\hline & $\begin{array}{l}\text { Sprains and strains of other and } \\
\text { unspecified parts of back }\end{array}$ & 847 \\
\hline & $\begin{array}{l}\text { Spinal cord injury without evidence of } \\
\text { spinal bone injury }\end{array}$ & 952 \\
\hline & Injury to nerve roots and spinal plexus & 953 \\
\hline & $\begin{array}{l}\text { Injury to other nerve(s) of trunk } \\
\text { excluding shoulder and pelvic girdles }\end{array}$ & 954 \\
\hline \multirow{16}{*}{$\begin{array}{l}\text { Tenth revision } \\
\text { (2016-2017) }\end{array}$} & Ankylosing spondylitis & M45 \\
\hline & Other inflammatory spondylopathies & M46 \\
\hline & Spondylosis & M47 \\
\hline & Other spondylopathies & M48 \\
\hline & $\begin{array}{l}\text { Spondylopathies in diseases classified } \\
\text { elsewhere }\end{array}$ & M49 \\
\hline & Cervical disc disorders & M50 \\
\hline & $\begin{array}{l}\text { Thoracic, thoracolumbar, and } \\
\text { lumbosacral intervertebral disc disorders }\end{array}$ & M51 \\
\hline & $\begin{array}{l}\text { Other and unspecified dorsopathies, not } \\
\text { elsewhere specified }\end{array}$ & M53 \\
\hline & Dorsalgia & M54 \\
\hline & $\begin{array}{l}\text { Fracture of cervical vertebra and other } \\
\text { parts of neck }\end{array}$ & S12 \\
\hline & $\begin{array}{l}\text { Dislocation and sprain of joints and } \\
\text { ligaments at neck level }\end{array}$ & S13 \\
\hline & $\begin{array}{l}\text { Injury of nerves and spinal cord at neck } \\
\text { level }\end{array}$ & S14 \\
\hline & $\begin{array}{l}\text { Injury of nerves and spinal cord at thorax } \\
\text { level }\end{array}$ & $\mathrm{S} 24$ \\
\hline & Fracture of lumbar spine and pelvis & S32 \\
\hline & $\begin{array}{l}\text { Dislocation and sprain of joints and } \\
\text { ligaments of lumbar spine and pelvis }\end{array}$ & S 33 \\
\hline & $\begin{array}{l}\text { Injury of lumbar and sacral spinal cord } \\
\text { and nerves at abdomen, lower back, and } \\
\text { pelvis level }\end{array}$ & S34 \\
\hline
\end{tabular}

A full ICD (International Classification of Diseases) code is assigned to each complaint reported by participants during household interviews. Full codes are aggregated to first three digits by the MEPS

Since MEPS started using the 10th version of ICD in 2016, the compatibility of the 9th and 10th versions' codes for back pain were ensured by way of matching based on General Equivalence Mappings

receipt of medications in round four, as weight status is not measured until round three, and we wish to maintain temporal ordering between the exposure and outcome. We exclude persons who were pregnant or had a diagnosis of cancer in rounds three or four, leaving a sample size of 5999 persons with back pain who completed the SAQ.

\section{Measures}

Our primary exposure of interest is weight status. Using height and weight data from round three, MEPS calculates body mass index (BMI), which we use to create categorical measures of weight status following standard guidelines: ${ }^{53}$ underweight (BMI: <18.5), normal weight (18.5-24.9), 
overweight (25-29.9), class I obesity (30-34.9), and class II/III obesity $(\geq 35)$.

Our outcome of interest is the receipt of Rx analgesics for back pain. The MEPS collects data on Rx medications in each round of the household interview, and supplements this information using administrative data from pharmacies. Respondents are asked to provide the names of all $\mathrm{Rx}$ medications that were purchased or obtained through other means (e.g., free samples) during the round and identify the pharmacy where the prescriptions had been filled. Respondents are also asked to report on the condition for which the medication was prescribed, and our outcome targets analgesics prescribed for back pain. To improve reporting accuracy, respondents are asked to show containers and boxes to the interviewer. Of note, the MEPS only includes prescriptions that were filled and does not discriminate between new prescriptions and refills. Each prescription represents the purchase of a single drug product.

We examine two basic categories of analgesics: (1) opioids and (2) non-opioid analgesics (henceforth referred to as "non-opioids"). The categories are defined using Multum Lexicon, a classification system for all approved drug products in the U.S. market. ${ }^{54}$ Opioids include drugs categorized in Multum as "Opioid analgesics" or "Opioid analgesic combinations." Opioids with the following generic names are excluded because their primary use is not pain treatment: buprenorphine-naloxone, buprenorphine, and methadone. Non-opioids refer to drugs categorized in the following Multum classes: "Non-steroidal antiinflammatory drugs (NSAIDs)," "Salicylates," "Analgesic combinations," "COX-2 inhibitors," or "Miscellaneous analgesics." It also includes doxepin, gabapentin, and pregabalin, which are frequently used for pain management. ${ }^{55}$. 56

As obesity is associated with an increased burden of pain, we adjust the models for pain interference. In the SAQ, respondents are asked, "During the past 4 weeks, how much did pain interfere with your normal work (including both work outside the home and housework)?" and responses are "not at all," "a little bit," "moderately," "quite a bit," and "extremely." We code responses using an ordinal variable with a range of one to five. We also account for the frequency of healthcare visits for back pain, as it may be associated with both weight status and the likelihood of receiving pain medications. ${ }^{34-36}$. 57, 58 During household interviews, MEPS collects information on visits to outpatient departments, office-based providers, emergency rooms, and inpatient stays, including the health conditions associated with each event. The frequency of healthcare visits equals the sum of all visits for back pain during the reference period for round four.

We also adjust for survey year and sociodemographic variables: sex, age, race-ethnicity, education, household income, marital status, insurance status, and region of residence. ${ }^{50,51}$ Age is modeled using both a continuous variable and a squared term to account for its non-linear relationship with the outcome. Other covariates are modeled using categorical indicators shown in Table 2.

\section{Statistical Analysis}

We use a series of multivariate regression models to examine the association of weight status with the receipt of analgesic prescriptions as the outcome, adjusting for covariates. First, we use logistic regression to examine the receipt of any pain prescription as a dichotomous outcome. Second, we use multinomial logistic regression to examine the following fourcategory outcome: opioid only, non-opioid only, a combination of opioid and non-opioid, and no prescription. Here, we

Table 2 Sample characteristics $(N=5791)$, MEPS, 2010-2017

\begin{tabular}{|c|c|}
\hline Variable & $\begin{array}{l}\text { Frequency } \\
(\%)^{\gamma}\end{array}$ \\
\hline \multicolumn{2}{|l|}{ Weight status } \\
\hline Underweight & 1.19 \\
\hline Normal & 27.36 \\
\hline Overweight & 33.10 \\
\hline Class I obesity & 21.70 \\
\hline Class II/III obesity & 16.65 \\
\hline Received any pain prescription & 29.67 \\
\hline Opioids only & 15.36 \\
\hline Non-opioids only & 9.83 \\
\hline Opioids and non-opioids & 4.48 \\
\hline Age, mean $(\mathrm{SE})^{\ddagger}$ & $52.47(0.29)$ \\
\hline Female sex & 54.77 \\
\hline \multicolumn{2}{|l|}{ Race-ethnicity } \\
\hline Hispanic & 10.38 \\
\hline Non-Hispanic white & 74.56 \\
\hline Non-Hispanic black & 8.64 \\
\hline Non-Hispanic Asian & 3.50 \\
\hline Other & 2.92 \\
\hline \multicolumn{2}{|l|}{ Education } \\
\hline$<$ High school & 11.59 \\
\hline High school graduate & 29.50 \\
\hline Some college & 29.65 \\
\hline College graduate & 29.25 \\
\hline \multicolumn{2}{|l|}{ Marital status } \\
\hline Married & 56.06 \\
\hline Never married & 18.10 \\
\hline Other (separated, divorced, widowed) & 25.84 \\
\hline \multicolumn{2}{|l|}{ Household income $^{\S}$} \\
\hline Negative or poor $(<100)$ & 12.63 \\
\hline Near poor $(100-125)$ & 4.58 \\
\hline Low income $(125-200)$ & 12.71 \\
\hline Middle income (200-400) & 28.92 \\
\hline High income $(>400)$ & 41.16 \\
\hline \multicolumn{2}{|l|}{ Insurance } \\
\hline Uninsured & 10.97 \\
\hline Only public insurance & 27.44 \\
\hline $\begin{array}{l}\text { Any private insurance with or without public } \\
\text { insurance }\end{array}$ & 61.59 \\
\hline Pain interference (range 1-5), mean (SE) & $2.69(0.02)$ \\
\hline Healthcare visits, mean (SE) & $3.03(0.08)$ \\
\hline \multicolumn{2}{|l|}{ Region } \\
\hline Northeast & 19.24 \\
\hline Midwest & 24.25 \\
\hline West & 24.62 \\
\hline South & 31.88 \\
\hline \multicolumn{2}{|c|}{$\begin{array}{l}\text { All estimates reflect survey weight } \\
\text { tUnless indicated otherwise } \\
\text { Top-coded at } 85 \\
\text { Income categories are based on the federal poverty line (i.e., } 100= \\
100 \% \text { of the poverty line) } \\
\text { "Insurance status on the interview day } \\
\text { "Top-coded at } 15\end{array}$} \\
\hline
\end{tabular}


again compare treatment to no treatment, but allow the treatment outcomes to vary in potency. Third, we use logistic regression to examine the receipt of an opioid prescription among those with any pain prescription. Hence, conditional on treatment, we ask whether obesity is associated with receipt of an opioid. We also check for interactions of weight status with sex and race/ethnicity and conduct the following sensitivity tests: limiting the sample to household proxies (for whom all information is self-reported), and excluding doxepin, gabapentin, and pregabalin from the definition of non-opioid analgesics. Unlike the other non-opioids, they are not classified as "Analgesics" under Multum.

Respondents with missing data are excluded from analyses. The overall rate of missing data is $3.5 \%$, with a range of 2.1 to $5.2 \%$ by year. Our final sample includes 5791 adults. Analyses are conducted using STATA version 16.0 (StataCorp LP, College Station, TX). All analyses use the "svy" command to account for the complex multistage sample design. ${ }^{44}$ The study is classified as exempt by the IRB office of New York University because we conduct secondary analyses of de-identified, existing data. Datasets generated/analyzed in this study are available from the corresponding author upon reasonable request.

\section{RESULTS}

Table 2 displays the sample characteristics. The prevalence of classes I and II/III obesity is $21.7 \%$ and $16.7 \%$, respectively. In the overall sample, $29.7 \%$ received a prescription for any type of pain medication, $15.4 \%$ for opioids only, $9.8 \%$ for nonopioids only, and $4.5 \%$ for both opioids and non-opioids. The prevalence of pain medication use is comparable to prior estimates among individuals with back pain. ${ }^{51,59}$ Table 3 shows the unadjusted prevalence of the outcomes by weight status. For the first three outcomes (any medication, opioids only, and non-opioids only), there is a monotonic increase in the prevalence of prescriptions when going from normal weight to class II/III obesity, suggesting an unadjusted association between increased weight status and a higher probability of receiving Rx analgesics.

Table 4 displays logistic regression results for the odds of receiving any pain prescription for back pain. Adjusting for pain interference and other covariates, adults who are overweight or obese have significantly higher odds of receiving any pain prescription relative to persons with normal weight, and the odds ratios show a monotonic increase with weight status (overweight: 1.24 [95\% CI = 1.03, 1.51]; obesity I: OR $=1.30[95 \% \mathrm{CI}=1.04,1.63]$; obesity $\mathrm{II} / \mathrm{III}: \mathrm{OR}=1.72[95 \%$ $\mathrm{CI}=1.36,2.18])$.

Table 5 displays multinomial regression results for the odds of an outcome in the following categories: (1) opioids only, (2) non-opioids only, and (3) both opioids and non-opioids. No prescription is the referent category. Individuals with grade II/ III obesity have significantly higher odds of receiving opioids only relative to those with normal weight (OR $=1.53$ [95\% CI $=1.16-2.02]$ ). For non-opioids only, being overweight or obese is associated with higher odds of receiving prescriptions relative to normal weight (overweight: $\mathrm{OR}=1.42[95 \% \mathrm{CI}=$ $1.07-1.88]$; obesity I: OR $=1.55[95 \% \mathrm{CI}=1.07-2.23]$; obesity II/III: OR $=1.77$ [95\% CI $=1.21-2.60]$ ). Only class II/III obesity is significantly associated with higher odds of receiving prescriptions for both opioids and non-opioids relative to the normal weight category $(\mathrm{OR}=2.48[95 \% \mathrm{CI}=$ 1.44-4.29]). The ORs for receiving opioids only and nonopioids only increase in a monotonic fashion from normal weight to obesity II/III.

Table 3 Unadjusted prevalence of pain prescriptions by weight status $(N=5791)$, MEPS, 2010-2017

\begin{tabular}{|c|c|c|c|c|c|c|}
\hline \multirow[t]{2}{*}{ Receipt of prescriptions } & \multirow{2}{*}{$\begin{array}{l}\text { Full sample } \\
(N=5791)\end{array}$} & \multicolumn{5}{|l|}{ BMI category } \\
\hline & & $\begin{array}{l}\text { Underweight } \\
(N=72)\end{array}$ & $\begin{array}{l}\text { Normal weight } \\
(N=1461)\end{array}$ & $\begin{array}{l}\text { Overweight } \\
(N=1895)\end{array}$ & $\begin{array}{l}\text { Obesity I } \\
(N=1285)\end{array}$ & $\begin{array}{l}\text { Obesity II/III } \\
(N=1078)\end{array}$ \\
\hline $\begin{array}{l}\text { Any pain medication } \\
\% \\
(95 \% \mathrm{CI}) \\
p \text { value }^{\dagger}\end{array}$ & $\begin{array}{l}29.67 \\
(28.03-31.37) \\
-\end{array}$ & $\begin{array}{l}26.98 \\
(16.03-41.70) \\
-\end{array}$ & $\begin{array}{l}21.78 \\
(19.16-24.64)\end{array}$ & $\begin{array}{l}28.50 \\
(25.83-31.32) \\
<\end{array}$ & $\begin{array}{l}32.64 \\
(29.64-35.80)\end{array}$ & $\begin{array}{l}41.30 \\
(37.75-44.94)\end{array}$ \\
\hline $\begin{array}{l}\text { Opioids only } \\
\% \\
(95 \% \text { CI }) \\
p \text { value }^{\dagger}\end{array}$ & $\begin{array}{l}15.36 \\
(14.17-16.63) \\
-\end{array}$ & $\begin{array}{l}15.66 \\
(8.42-27.26) \\
-\end{array}$ & $\begin{array}{l}11.58 \\
(9.77-13.68)\end{array}$ & $\begin{array}{r}14.52 \\
(12.55-16.74) \\
<\end{array}$ & $\begin{array}{l}17.40 \\
(15.04-20.04)\end{array}$ & $\begin{array}{l}20.58 \\
(17.81-23.65)\end{array}$ \\
\hline $\begin{array}{l}\text { Non-opioids only } \\
\% \\
(95 \% \mathrm{CI}) \\
p \text { value }^{\dagger}\end{array}$ & $\begin{array}{l}9.83 \\
(8.97-10.76) \\
-\end{array}$ & $\begin{array}{l}9.24 \\
(3.49-22.28) \\
-\end{array}$ & $\begin{array}{l}7.27 \\
(5.77-9.12)\end{array}$ & $\begin{array}{l}9.74 \\
(8.32-11.38)\end{array}$ & $\begin{array}{l}11.28 \\
(9.54-13.29)\end{array}$ & $\begin{array}{l}12.36 \\
(9.99-15.18)\end{array}$ \\
\hline $\begin{array}{l}\text { Opioids and non-opioids } \\
\% \\
(95 \% \mathrm{CI}) \\
p \text { value }^{\dagger}\end{array}$ & $\begin{array}{l}4.48 \\
(3.90-5.14) \\
-\end{array}$ & $\begin{array}{l}2.08 \\
(0.72-5.85) \\
-\end{array}$ & $\begin{array}{l}2.93 \\
(2.14-4.00)\end{array}$ & $\begin{array}{l}4.23 \\
(3.27-5.47)\end{array}$ & $\begin{array}{l}3.97 \\
(2.85-5.50)\end{array}$ & $\begin{array}{l}8.36 \\
(6.32-10.97)\end{array}$ \\
\hline
\end{tabular}

All estimates reflect survey weight

Htalicized numbers indicate statistical significance of differences in the proportion of outcomes across weight categories based on the Pearson chisquare statistic, which had been corrected to accommodate the survey design 
Table 4 Adjusted relative odds of receiving any pain prescriptions $(N=5791)$, MEPS, 2010-2017

\begin{tabular}{|c|c|c|c|c|c|}
\hline \multirow[t]{2}{*}{$\overline{\text { Receipt of any pain prescription }}$} & \multicolumn{5}{|c|}{ BMI category $\left(\mathrm{kg} / \mathrm{m}^{2}\right)$} \\
\hline & $\begin{array}{l}\text { Underweight } \\
(<18.5)\end{array}$ & $\begin{array}{l}\text { Normal weight } \\
(18.5-24.9)\end{array}$ & $\begin{array}{l}\text { Overweight } \\
(25-29.9)\end{array}$ & $\begin{array}{l}\text { Obesity I } \\
(30-34.9)\end{array}$ & Obesity II/III $(\leq 35)$ \\
\hline $\begin{array}{l}\text { OR }(95 \% \text { CI }) \\
p \text { value }\end{array}$ & $\begin{array}{l}1.00(0.50-2.03) \\
0.99\end{array}$ & $\underline{\operatorname{Ref}}$ & $\begin{array}{l}1.24(1.03-1.51) \\
0.03\end{array}$ & $\begin{array}{l}1.30(1.04-1.63) \\
0.02\end{array}$ & $\begin{array}{l}1.72(1.36-2.18) \\
<0.001\end{array}$ \\
\hline
\end{tabular}

All estimates reflect survey weight

The model is adjusted for pain interference, visit frequency, age, squared age, sex, race-ethnicity, household income, education, marital status, insurance status, region, and survey year

Italicized numbers indicate statistical significance

Table 6 shows logistic regression results for the odds of receiving an opioid $\mathrm{Rx}$ among those who received any analgesic $\mathrm{Rx}$ for back pain $(N=1895)$. The estimates for all weight categories are statistically non-significant, suggesting that, adjusting for pain interference and other covariates, weight status is not associated with differential odds of receiving an opioid over other pain medications. Lastly, we did not find significant interactions between weight status and sex or race/ ethnicity in our models, and sensitivity analyses that limited the sample to household proxies and excluded certain nonopioids that are not technically listed as "Analgesics" in Multum did not show meaningful differences in estimates for weight status (Appendices 1-4).

\section{DISCUSSION}

Although prior research on weight stigma and disparities in care raises the concern that individuals with obesity may be less likely to receive $\mathrm{Rx}$ medications for the treatment of pain, we did not find evidence of reduced access. On the contrary, in a nationally representative sample of adults with back pain, obesity was associated with higher odds of receiving opioids and non-opioids, despite adjustments for pain interference. Moreover, conditional on having a pain prescription for back pain, clinicians' propensity to provide more potent medications (i.e., opioids) did not differ by patients' weight status.
While some studies show that patients with obesity are less likely to receive certain types of medical care, the findings in this literature are actually mixed, with others finding no differences in the quality of care. ${ }^{21,22,60,61}$ Moreover, some studies find that patients with obesity are, in fact, more likely to receive preventive care for cardiovascular disease and diabetes (e.g., lipid and hemoglobin $\mathrm{A} 1 \mathrm{C}$ testing). ${ }^{21,60}$

Our work on pain treatment similarly suggests that individuals with obesity are not subject to reduced care, at least in the context of back pain, a major source of disability and reduced quality of life in the U.S. ${ }^{30,}{ }^{31}$ Obesity is associated with significantly higher odds of receiving both opioids and nonopioids, despite controlling for pain interference, healthcare visit frequency, insurance status, and a large number of sociodemographic factors. It is important to note, though, that our measure of pain interference may capture only one aspect of the burden of pain, and there can be residual variation by weight status in the need for pain relief, i.e., individuals with obesity may be more likely to experience and report pain outside the realm of pain interference. Increased physiologic sensitivity to pain among persons with obesity ${ }^{32,62,63}$ is another source of residual variation in the burden of pain that may not have been fully captured by our measure. Although our data do not permit an in-depth assessment of the clinical appropriateness of any given pain prescription for back pain, interference with work activities is a major dimension of the experienced burden of pain, ${ }^{64-66}$ and the strong positive

Table 5 Adjusted relative odds of receiving pain prescriptions by drug outcome category $(N=5791)$, MEPS, 2010-2017

\begin{tabular}{|c|c|c|c|c|c|}
\hline \multirow[t]{2}{*}{ Outcome } & \multicolumn{5}{|l|}{ BMI Category $\left(\mathrm{kg} / \mathrm{m}^{2}\right)$} \\
\hline & Underweight $(<18.5)$ & $\begin{array}{l}\text { Normal weight } \\
\text { (18.5-24.9) }\end{array}$ & $\begin{array}{l}\text { Overweight } \\
(25-29.9)\end{array}$ & Obesity I (30-34.9) & Obesity II/III $(\leq 35)$ \\
\hline $\begin{array}{l}\text { No pain prescription } \\
\text { Opioids only }\end{array}$ & Ref & & & & \\
\hline OR $(95 \% \mathrm{CI})$ & $1.09(0.51-2.31)$ & Ref & $1.11(0.85-1.44)$ & $1.20(0.90-1.59)$ & $1.53(1.16-2.02)$ \\
\hline $\begin{array}{l}p \text { value } \\
\text { Non-opioids only }\end{array}$ & 0.83 & - & 0.45 & 0.21 & 0.003 \\
\hline $\begin{array}{l}\text { OR }(95 \% \text { CI }) \\
p \text { value } \\
\text { Opioids and non-opioids }\end{array}$ & $\begin{array}{l}1.11(0.37-3.31) \\
0.86\end{array}$ & $\underline{\operatorname{Ref}}$ & $1.42(1.07-1.88)$ & $\begin{array}{l}1.55(1.07-2.23) \\
0.02\end{array}$ & $\begin{array}{l}1.77(1.21-2.60) \\
0.004\end{array}$ \\
\hline $\begin{array}{l}\text { Opioids and non-opioids } \\
\text { OR }(95 \% \text { CI }) \\
p \text { value }\end{array}$ & $\begin{array}{l}0.55(0.17-1.85) \\
0.33\end{array}$ & Ref & $\begin{array}{l}1.39(0.85-2.26) \\
0.19\end{array}$ & $\begin{array}{l}1.15(0.71-1.86) \\
0.58\end{array}$ & $\begin{array}{l}2.48(1.44-4.29) \\
0.001\end{array}$ \\
\hline
\end{tabular}

All estimates reflect survey weight

The model is adjusted for pain interference, visit frequency, age, squared age, sex, race-ethnicity, household income, education, marital status, insurance status, region, and survey year

Italicized numbers indicate statistical significance 
Table 6 Adjusted relative odds of receiving an opioid prescription among individuals receiving any pain prescriptions $(N=1895)$, MEPS, 20102017

\begin{tabular}{|c|c|c|c|c|c|}
\hline \multirow[t]{2}{*}{ Receipt of opioids } & \multicolumn{5}{|l|}{ BMI category $\left(\mathrm{kg} / \mathrm{m}^{2}\right)$} \\
\hline & Underweight $(<18.5)$ & Normal weight (18.5-24.9) & Overweight (25-29.9) & Obesity I (30-34.9) & Obesity II/III ( $\leq 35)$ \\
\hline $\begin{array}{l}\text { OR }(95 \% \text { CI }) \\
p \text { value }\end{array}$ & $\begin{array}{l}0.97(0.36-2.60) \\
0.95\end{array}$ & Ref & $\begin{array}{l}0.87(0.61-1.25) \\
0.44\end{array}$ & $\begin{array}{l}0.87(0.58-1.30) \\
0.49\end{array}$ & $\begin{array}{l}1.06(0.69-1.63) \\
0.78\end{array}$ \\
\hline
\end{tabular}

All estimates reflect survey weight

The model is adjusted for pain interference, visit frequency, age, squared age, sex, race-ethnicity, household income, education, marital status, insurance status, region, and survey year

associations we find suggest that undertreatment is less likely. In fact, the positive association we find between obesity and the receipt of pain medications could even represent overtreatment.

A central mediator of racial-ethnic disparities in analgesic prescribing has been found to be the discounting of racial minority patients' burden of pain by providers. ${ }^{1,2}$ For instance, racial minorities were more likely to have their burden of pain underestimated by providers and less likely to have their level of pain documented on medical records. ${ }^{1,2}$ In the case of back pain patients with obesity, providers may be less likely to discount their burden of pain because obesity itself is viewed as a significant contributor to back pain. ${ }^{32-37}$ This is in keeping with studies finding that patients who are obese are more likely to receive preventive and recommended care for cardiovascular disease and diabetes, conditions where obesity itself is a major risk factor. ${ }^{21,60}$ While our study suggests that individuals with obesity are unlikely to be under-treated for pain, over-treatment, if it is the case, would be concerning because, in contrast to recommended preventive care, increased receipt of opioids is a risk factor for undesirable health outcomes (e.g., overdose) ${ }^{67}$

While obesity has been implicated in increased prevalence of pain and pain medication use, ${ }^{40,68}$ our study focuses, instead, on whether there are disparities in the treatment of pain by restricting the sample to those with back pain and adjusting for pain interference. Future work should consider of other conditions that warrant treatment with Rx pain medication and whether patients with obesity could, in fact, be overtreated for pain. Research on the latter requires more detailed, clinical data. One could, for example, examine the incidence of side-effects or whether recommended doses have been exceeded. Future work could also consider whether obesity is associated with disparities in access to treatments for opioid abuse. Our work, however, did not find that obesity is associated with the receipt of opioids over other types of analgesics.

This study has limitations. First, as discussed above, our data do not allow for a detailed, clinical assessment of the need for any given pain prescription. For example, we do not know what the patient reported with respect to pain during a specific clinical encounter. This type of information is not typically available in large, population-based surveys. Our findings of a strong positive association do, however, suggest that undertreatment among those with obesity is less likely in a nationally representative sample of individuals with a common source of pain. Second, the MEPS collects information from household proxies. Estimates from sensitivity analyses limited to self-reporters, however, are comparable to those of the full sample. Third, we do not differentiate between acute and chronic pain when identifying persons with back pain. Fourth, the MEPS did not collect data on over-the-counter (OTC) medications, so our findings only pertain to the use of $\mathrm{Rx}$ medication. Future work could incorporate the use of OTC NSAIDs, which are frequently used to manage back pain symptoms. ${ }^{69,70}$

\section{CONCLUSIONS}

Our findings collectively suggest that for back pain, patients with obesity are more likely to receive $\mathrm{Rx}$ pain medications than those in the normal weight category. Hence, the possibility of weight-based undertreatment is not supported. Conditional on having a pain prescription, individuals who are obese are neither more nor less likely to receive an opioid. As obesity is associated with multiple key risk factors for back pain, it is reassuring to find that those with the highest burden of back pain do not experience reduced access to Rx analgesics. The possibility of over-treatment, however, may warrant further research.

Corresponding Author: Virginia W. Chang, MD, PhD; Department of Population Health, Grossman School of Medicine, New York University, New York, NY, USA (e-mail: vc43@nyu.edu).

\section{Compliance with Ethical Standards:}

Conflict of Interest: Gawon Cho participated in all tasks involved in the production of the manuscript and had access to the data. She formulated the research question and conducted literature search, which provided the basis for the project. She also led the empirical analyses and organized the findings into the manuscript. Gawon Cho has nothing to disclose.

Virginia Chang supervised Gawon Cho's work throughout the course of the project. She contributed to conceptualizing the research question, choosing the dataset, designing the empirical analyses, and interpreting the results. She also contributed substantially to writing the manuscript. Virginia Chang has nothing to disclose. 


\section{REFERENCES}

1. Cintron A, Morrison RS. Pain and ethnicity in the United States: A systematic review. J Palliat Med 2006;9(6):1454-1473.

2. Mossey $\mathbf{J M}$. Defining racial and ethnic disparities in pain management. Clin Orthop Relat Res 2011;469(7):1859-1870.

3. Anderson KO, Green CR, Payne R. Racial and ethnic disparities in pain: causes and consequences of unequal care. J Pain 2009;10(12):1187-1204

4. Green CR, Anderson KO, Baker TA, et al. The unequal burden of pain: confronting racial and ethnic disparities in pain. Pain Med 2003;4(3):277294.

5. Todd KH, Deaton C, D'Adamo AP, Goe L. Ethnicity and analgesic practice. Ann Emerg Med 2000;35(1):11-16.

6. Heins JK, Heins A, Grammas M, Costello M, Huang K, Mishra S. Disparities in analgesia and opioid prescribing practices for patients with musculoskeletal pain in the emergency department. J Emerg Nurs 2006;32(3):219-224.

7. LeResche L. Defining Gender Disparities in Pain Management. Clin Orthop Relat Res 2011;469(7):1871-1877.

8. Raftery KA, Smith-Coggins $\mathbf{R}$, Chen AH. Gender-associated differences in emergency department pain management. Ann Emerg Med 1995;26(4):414-421.

9. Safdar B, Heins A, Homel $\mathbf{P}$, et al. Impact of physician and patient gender on pain management in the emergency department-a multicenter study. Pain Med 2009;10(2):364-372.

10. Pokela N, Simon Bell J, Lihavainen $\mathbf{K}$, Sulkava $\mathbf{R}$, Hartikainen $\mathbf{S}$. Analgesic use among community-dwelling people aged 75 years and older: A population-based interview study. Am J Geriatr Pharmacother 2010;8(3):233-244

11. McDonald DD. Gender and ethnic stereotyping and narcotic analgesic administration. Res Nurs Health 1994;17(1):45-49.

12. Budd GM, Mariotti M, Graff $\mathbf{D}$, Falkenstein $\mathbf{K}$. Health care professionals' attitudes about obesity: An integrative review. Appl Nurs Res 2011;24(3): 127-137.

13. Puhl RM, Heuer CA. The Stigma of Obesity: A Review and Update. Obesity. 2009;17(5):941-964.

14. Schwartz MB, Chambliss HON, Brownell KD, Blair SN, Billington C Weight Bias among Health Professionals Specializing in Obesity. Obes Res 2003;11(9): 1033-1039.

15. Puhl RM, Heuer CA. Obesity stigma: important considerations for public health. Am J Public Health 2010;100(6): 1019-1028.

16. Phelan SM, Burgess DJ, Yeazel MW, Hellerstedt WL, Griffin JM, van Ryn M. Impact of weight bias and stigma on quality of care and outcomes for patients with obesity. Obes Rev 2015;16(4):319-326.

17. Hatzenbuehler ML, Phelan JC, Link BG. Stigma as a fundamental cause of population health inequalities. Am J Public Health 2013; 103(5):813-821

18. Huizinga MM, Bleich SN, Beach MC, Clark JM, Cooper LA. Disparity in physician perception of patients' adherence to medications by obesity status. Obesity. 2010;18(10):1932-1937.

19. Kaposy C. The influence of the stigma of obesity on H1N1 influenza vaccine sequencing in Canada in 2009. Vaccine. 2011;29(52):9607-9610.

20. Teixeira ME, Budd GM. Obesity stigma: a newly recognized barrier to comprehensive and effective type 2 diabetes management. J Am Acad Nurse Pract 2010;22(10):527-533.

21. Littman AJ, Koepsell TD, Forsberg CW, Boyko EJ, Yancy Jr WS. Preventive care in relation to obesity: an analysis of a large, national survey. Am J Prev Med 2011;41(5):465-472.

22. Fagan HB, Wender R, Myers RE, Petrelli N. Obesity and cancer screening according to race and gender. J Obes 2011;2011.

23. Hernandez-Boussard T, Ahmed SM, Morton JM. Obesity disparities in preventive care: findings from the National Ambulatory Medical Care Survey, 2005-2007. Obesity. 2012;20(8):1639-1644.

24. Harris JA, Byhoff E, Perumalswami CR, Langa KM, Wright AA, Griggs JJJAoim. The relationship of obesity to hospice use and expenditures: a cohort study. Ann Intern Med 2017;166(6):381-389.

25. Giori NJ, Amanatullah DF, Gupta S, Bowe T, Harris AHS. Risk Reduction Compared with Access to Care: Quantifying the Trade-Off of Enforcing a Body Mass Index Eligibility Criterion for Joint Replacement. J Bone Joint Surg Am 2018;100(7):539-545.

26. Shapiro JA, Narayanan AS, Taylor PR, Olcott CW, Del Gaizo DJ. Fate of the Morbidly Obese Patient Who Is Denied Total Joint Arthroplasty. J Arthroplast. 2020;35(6, Supplement):S124-S128.

27. Gudzune KA, Beach MC, Roter DL, Cooper LA. Physicians build less rapport with obese patients. Obesity. 2013;21(10):2146-2152.
28. Hebl MR, Xu J. Weighing the care: physicians' reactions to the size of a patient. Int $\mathrm{J}$ Obes 2001;25(8):1246.

29. Persky S, Eccleston CP. Medical student bias and care recommendations for an obese versus non-obese virtual patient. Int $\mathrm{J}$ Obes 2011;35(5):728-735

30. Mokdad AH, Ballestros K, Echko M, et al. The state of US health, 1990 2016: burden of diseases, injuries, and risk factors among US states. JAMA. 2018;319(14):1444-1472.

31. McGrath R, Al Snih S, Markides K, Hall O, Peterson M. The burden of health conditions for middle-aged and older adults in the United States: disability-adjusted life years. BMC Geriatr 2019;19(1):100.

32. Walsh TP, Arnold JB, Evans AM, Yaxley A, Damarell RA, Shanahan EM. The association between body fat and musculoskeletal pain: a systematic review and meta-analysis. BMC Musculoskelet Disord 2018;19(1):233.

33. Shiri R, Karppinen J, Leino-Arjas $\mathbf{P}$, Solovieva S, Viikari-Juntura E. The association between obesity and low back pain: a meta-analysis. Am J Epidemiol 2009;171(2):135-154.

34. Anandacoomarasamy A, Caterson I, Sambrook P, Fransen M, March L. The impact of obesity on the musculoskeletal system. Int $\mathrm{J}$ Obes 2008;32(2):211-222.

35. Zhang T-T, Liu Z, Liu Y-L, Zhao J-J, Liu D-W, Tian Q-B. Obesity as a risk factor for low back pain: a meta-analysis. J Clin Spine Surg 2018;31(1):22-27.

36. Dario AB, Ferreira ML, Refshauge KM, Lima TS, Ordonana JR, Ferreira PH. The relationship between obesity, low back pain, and lumbar disc degeneration when genetics and the environment are considered: a systematic review of twin studies. Spine J 2015;15(5):1106-1117

37. Ferreira PH, Beckenkamp P, Maher CG, Hopper JL, Ferreira ML. Nature or nurture in low back pain? Results of a systematic review of studies based on twin samples. Eur J Pain 2013;17(7):957-971.

38. Shiri R, Lallukka T, Karppinen J, Viikari-Juntura E. Obesity as a risk factor for sciatica: a meta-analysis. Am J Epidemiol 2014;179(8):929937.

39. Stokes A, Berry KM, Collins JM, et al. The contribution of obesity to prescription opioid use in the United States. Pain. 2019;160(10):2255.

40. Stokes A, Lundberg DJ, Hempstead K, Berry KM, Baker JF, Preston SH. Obesity and Incident Prescription Opioid Use in the US, 2000-2015. Am J Prev Med 2020.

41. Chen I, Kurz J, Pasanen M, et al. Racial differences in opioid use for chronic nonmalignant pain. J Gen Intern Med 2005;20(7):593-598.

42. Moore C, Siu A, Maroney C, et al. Factors associated with reductions in patients' analgesia at hospital discharge. J Palliat Med 2006;9(1):41-49.

43. Medical Expenditure Panel Survey: Survey Background. https://meps. ahrq.gov/mepsweb/about_meps/survey_back.jsp. Accessed July 15th, 2019 .

44. Chowdhury SR, Machlin SR, Gwet KL. Sample Designs of the Medica Expenditure Panel Survey Household Component, 1996-2006 and 20072016. US Department of Health \& Human Services, Agency for Healthcare Research and Quality; 2019.

45. Cohen J. Design and methods of the Medical Expenditure Panel Survey, household component. US Department of Health and Human Services, Public Health Service, Agency for Healthcare Research and Quality; 1997.

46. Cohen SB. Design strategies and innovations in the medical expenditure panel survey. Med Care 2003:III5-III12.

47. MEPS Household Component Full Year Consolidated Data File. 20102017.

48. MEPS Survey Questionnaires. Agency for Healthcare Research and Quality website. https://www.meps.ahrq.gov/mepsweb/survey_comp/ survey.jsp. Accessed July 27, 2020.

49. Smith DL. Disparities in patient-physician communication for persons with a disability from the 2006 Medical Expenditure Panel Survey (MEPS). Disabil Health J 2009;2(4):206-215.

50. Luo X, Pietrobon R, Hey L. Patterns and trends in opioid use among individuals with back pain in the United States. Spine. 2004;29(8):884890

51. Luo X, Pietrobon R, Curtis LH, Hey LA. Prescription of nonsteroidal anti-inflammatory drugs and muscle relaxants for back pain in the United States. Spine. 2004;29(23):E531-E537.

52. Gebauer S, Salas J, Scherrer JF. Neighborhood socioeconomic status and receipt of opioid medication for new back pain diagnosis. J Am Board Fam Med 2017;30(6):775-783.

53. WHO Expert Committee on Physical Status. Physical status: The use of and interpretation of anthropometry, Report of a WHO Expert Committee. 1995 
54. Cerner. Multum MediSource Lexicon (MMSL). https://www.cerner.com/ about. Accessed December 4th, 2019.

55. Smith HS, Pappagallo M, Stahl SM. Essential Pain Pharmacology : The Prescriber's Guide. Cambridge, United Kingdom: Cambridge University Press; 2012

56. Stahl SM. Prescriber's Guide: Stahl's Essential Psychopharmacology. Cambridge University Press; 2017.

57. Chan G, Chen CT. Musculoskeletal effects of obesity. Curr Opin Pediatr 2009;21(1):65-70.

58. Kamble PS, Hayden $\mathbf{J}$, Collins $\mathbf{J}$, et al. Association of obesity with healthcare resource utilization and costs in a commercial population. Curr Med Res Opin 2018;34(7):1335-1343.

59. Shmagel A, Ngo L, Ensrud K, Foley R. Prescription Medication Use Among Community-Based U.S. Adults With Chronic Low Back Pain: A Cross-Sectional Population Based Study. J Pain 2018;19(10):1104-1112.

60. Chang VW, Asch DA, Werner RM. Quality of care among obese patients. JAMA. 2010;303(13):1274-1281.

61. Banerjea R, Findley PA, Sambamoorthi U. Disparities in preventive care by body mass index categories among women. Women Health 2008;47(4):1-17.

62. Price R, Asenjo J, Christou N, Backman S, Schweinhardt P. The role of excess subcutaneous fat in pain and sensory sensitivity in obesity. Eur J Pain 2013;17(9):1316-1326.
63. Rossi H, Luu A, DeVilbiss J, Recober A. Obesity increases nociceptive activation of the trigeminal system. Eur J Pain 2013;17(5):649-653.

64. Murray E, Franche R-L, Ibrahim S, et al. Pain-related work interference is a key factor in a worker/workplace model of work absence duration due to musculoskeletal conditions in Canadian nurses. J Occup Rehabil 2013;23(4):585-596.

65. Karoly P, Ruehlman LS. Psychosocial Aspects of Pain-Related Life Task Interference: An Exploratory Analysis in a General Population Sample. Pain Med 2007;8(7):563-572.

66. Wilson M. Integrating the Concept of Pain Interference into Pain Management. Pain Manag Nurs 2014;15(2):499-505.

67. Bohnert AS, Valenstein M, Bair MJ, et al. Association between opioid prescribing patterns and opioid overdose-related deaths. JAMA. 2011;305(13): 1315-1321.

68. Croft P, Blyth FM, van der Windt D. Chronic pain epidemiology: from aetiology to public health.Oxford Oxford University Press; 2010.

69. Wilcox CM. Cryer B, Triadafilopoulos G. Patterns of use and public perception of over-the-counter pain relievers: focus on nonsteroidal antiinflammatory drugs. J Rheumatol 2005;32(11):2218-2224.

70. Kuritzky L, Samraj GP. Nonsteroidal anti-inflammatory drugs in the treatment of low back pain. J Pain Res 2012;5:579.

Publisher's Note: Springer Nature remains neutral with regard to jurisdictional claims in published maps and institutional affiliations. 